\title{
BMJ Open Use and safety of azithromycin in neonates: a systematic review
}

\author{
Coral Smith, ${ }^{1}$ Oluwaseun Egunsola, ${ }^{1}$ Imti Choonara, ${ }^{1}$ Sailesh Kotecha, ${ }^{2}$ \\ Evelyne Jacqz-Aigrain, ${ }^{3}$ Helen Sammons ${ }^{1}$
}

To cite: Smith C,

Egunsola 0, Choonara I, et al. Use and safety of azithromycin in neonates: a systematic review. BMJ Open 2015;5: 008194 .

doi:10.1136/bmjopen-2015008194

- Prepublication history for this paper is available online. To view these files please visit the journal online (http://dx.doi.org/10.1136/ bmjopen-2015-008194).

Received 16 March 2015 Revised 14 October 2015 Accepted 2 November 2015

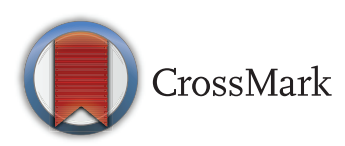

\footnotetext{
${ }^{1}$ Academic Division of Child Health, University of Nottingham, Derbyshire Children's Hospital, Derby, UK
}

${ }^{2}$ Department of Child Health, Institute of Molecular \& Experimental Medicine, Cardiff University School of Medicine, Wales Heart Research Institute, Heath Park, UK

${ }^{3}$ Univ Paris Diderot, Sorbonne Paris Cité, Department of Paediatric Pharmacology and Pharmacogenetics, Hôpital Robert Debré, Paris, France

Correspondence to Dr Oluwaseun Egunsola; mzxoe@nottingham.ac.uk

\section{ABSTRACT}

Objectives: To identify the use and adverse drug reactions associated with azithromycin in neonates. Setting: Databases MEDLINE (1948-August 2015), EMBASE (1980-August 2015) and Pubmed (August 2015) were searched for studies on azithromycin in neonates.

Participants: All studies involving neonates ( $<28$ days old) who have received at least a single dose of azithromycin for which safety was evaluated.

Primary and secondary outcome measures: The primary outcome was adverse event (AE) associated with use of azithromycin. Use of azithromycin in neonates was the secondary outcome.

Results: A total of 11 articles involving 473 neonates were identified. $371 \mathrm{AEs}$ were reported. Adverse events were mainly respiratory (358/1000 neonate), neurological (273/1000 neonates) and gastrointestinal (196/1000 neonates) in origin. Azithromycin significantly reduced the risk of bronchopulmonary dysplasia (BPD) in extremely premature neonates ( $R R=0.83,95 \% \mathrm{Cl} 0.71$ to $0.98, p=0.02$ ). There was no significant difference in the incidence of elevated liver enzymes between the azithromycin and placebo group $(p=0.76)$. There were four cases of infantile hypertrophic pyloric stenosis (IHPS).

Conclusions: Azithromycin significantly reduces the risk of BPD in preterm neonates. The relationship between azithromycin and IHPS requires further investigation.

\section{INTRODUCTION}

Azithromycin is a macrolide derivative of erythromycin. It is one of the most commonly prescribed antibiotics in children, with a prescription rate of between $4 \%$ and $14 \% .{ }^{1-3}$ Since its approval in the USA and Europe, ${ }^{45}$ it has been used extensively for the treatment of several paediatric infectious diseases. ${ }^{6}$ Prescription rate for respiratory tract infection in children is increasing. ${ }^{3}$

Owing to lack of efficacy and safety studies, oral and intravenous formulations are not recommended for children less than 6 months $^{7}$ and 16 years, ${ }^{8}$ respectively. The safety of azithromycin eye drops in children

\section{Strengths and limitations of this study}

This systematic review assessed the quality of all the randomised controlled trials (RCTs).

- RCTs, cohort studies and case reports were reviewed.

- Only a few studies of azithromycin in neonates have been published.

aged under 1 year is also unknown. ${ }^{9} \quad 10$ Gastrointestinal disorders such as diarrhoea, vomiting and abdominal pain are the most commonly reported side effects in paediatrics. ${ }^{11}$ Increased risk of arrhythmia and cardiovascular-related death in adults has been reported. ${ }^{12} 13$

The potential of azithromycin as a chemoprophylactic agent for bronchopulmonary dysplasia (BPD) in neonates is still under exploration. ureaplasma infection, which has been shown to be susceptible to the drug, ${ }^{14} 15$ is associated with BPD. ${ }^{16}{ }^{17}$ Despite limited efficacy and safety data, the US Centre for Disease Control (CDC) considers azithromycin as the first choice treatment and chemoprophylaxis of choice for pertussis in neonates. Treatment is recommended for $5-7$ days. $^{18}$

There is currently insufficient information on azithromycin treatment in neonates; therefore, this systematic review aims to evaluate all published data and reports on the safety and use of the drug in this age group.

\section{METHODS}

This review was carried out as per PRISMA guidelines. The systematic review protocol was not published.

\section{Search strategy}

The databases MEDLINE (1948-August 2015), EMBASE (1980-August 2015) and Pubmed (up to August 2015) were searched. Search words: 'preterm or neonat* or 
Figure 1 Summary of risk of bias.

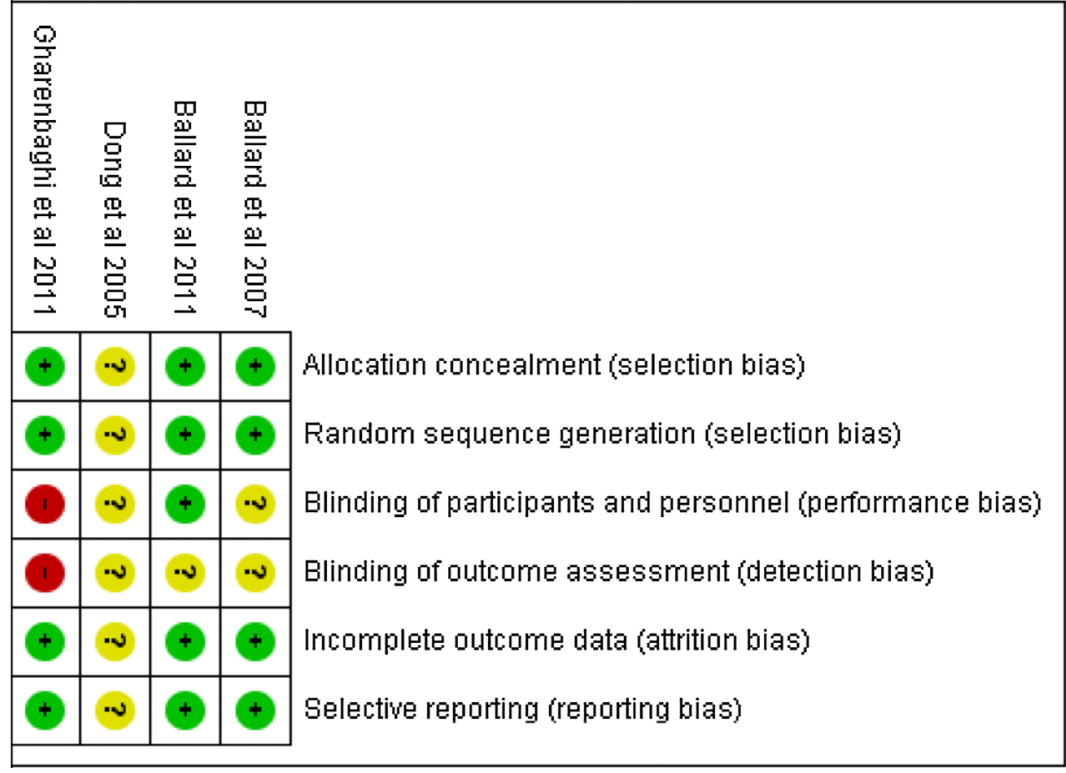

neonate* or newborn* or infan*' in title and abstract were combined with 'azithromycin' in title and abstract for all databases. Manual search of bibliography was also undertaken.

\section{Eligibility criteria}

Any published literature with documented involvement of neonates (birth to 28 days) administered azithromycin via any route of administration for any disease condition was included. There was no restriction on the type of study included, publication date and language of publication or inclusion of abstracts. Any article with involvement of the specified age group taking at least a single dose of azithromycin was assessed. Only articles with information on the safety of azithromycin were included, such as any mention of an adverse drug reaction, drug toxicity, drug, side effects or adverse event.

\section{Data quality assessment}

The randomised controlled trials (RCTs) were assessed using Cochrane collaboration's tool for assessing risk of bias, ${ }^{19}$ by two independent reviewers (figure 1). Studies with low risk of bias in at least four of the six parameters were included in the meta-analysis.

\section{Data collection and statistical analysis}

A single reviewer undertook eligibility assessment. Each title and available abstract was screened for appropriateness and relevant articles obtained. Articles were examined independently by a second reviewer to confirm they met inclusion criteria. Hand searching of references of articles was performed. Data were extracted from relevant articles on methodology, characteristics of trial participants (including condition and gestational age), number of neonates receiving azithromycin, number of participants in study, route of administration, dose, duration of azithromycin treatment, comparator drugs and adverse events.

Meta-analysis was carried out in Revman V.5.3. Relative risks and 95\% CIs were estimated for each RCT. Overall relative risks were calculated from the RCTs. Begg and Mazumdar's rank correlation tests were used to assess publication bias. No significant publication bias was found. Between-studies heterogeneity was assessed using a $\chi^{2}$ test where a $p$ value less than 0.05 indicated significant heterogeneity. Fixed effect models were used to produce summary relative risks and $95 \%$ CIs where heterogeneity did not exist. If statistical heterogeneity did exist then random effects models were applied.

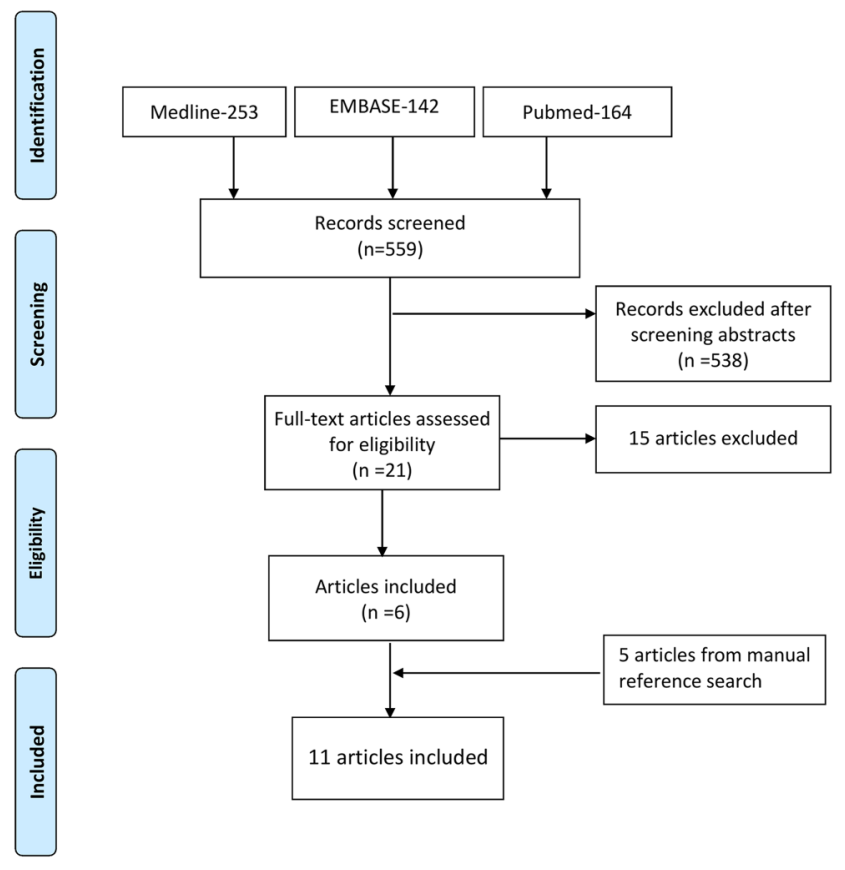

Figure 2 Flow chart of included articles. 
Table 1 Summary of all studies involving term and preterm neonates

\begin{tabular}{|c|c|c|c|c|c|c|c|c|c|}
\hline Reference & Study type & Comparator & $\begin{array}{l}\text { Age } \\
\text { (days) }\end{array}$ & $\begin{array}{l}\text { Number of } \\
\text { patients AZT }\end{array}$ & $\begin{array}{l}\text { Number of } \\
\text { patients } \\
\text { control }\end{array}$ & $\begin{array}{l}\text { Number of } \\
\text { AEs }\end{array}$ & AZT dose & Indication & Country \\
\hline Ballard et $a P^{20 *}$ & RCT & Placebo & $<3$ & 111 & 109 & 231 & $\begin{array}{l}10 \mathrm{mg} / \mathrm{kg} \times 1 \text { week then } 5 \mathrm{mg} / \mathrm{kg} / \\
\text { day } \times 5 \text { weeks (IV) }\end{array}$ & BPD & USA \\
\hline Ballard et $a^{p^{1 *}}$ & RCT & Placebo & $<3$ & 19 & 16 & 39 & $\begin{array}{l}10 \mathrm{mg} / \mathrm{kg} \times 1 \text { week then } 5 \mathrm{mg} / \mathrm{kg} / \\
\text { day } \times 5 \text { weeks (IV) }\end{array}$ & BPD & USA \\
\hline Gharehbaghi et $a^{22 *}$ & $\mathrm{RCT}$ & Nil & $<28$ & 56 & 52 & 52 & $\begin{array}{l}10 \mathrm{mg} / \mathrm{kg} \times 1 \text { week then } 5 \mathrm{mg} / \mathrm{kg} / \\
\text { day } \times 1 \text { week (oral) }\end{array}$ & $\mathrm{BPD}$ & Iran \\
\hline Dong $^{23}$ & $\mathrm{RCT}$ & Erythromycin & $<28$ & 25 & 21 & 18 & $\begin{array}{l}10 \mathrm{mg} / \mathrm{kg} \times 3 \text { days }(\mathrm{IV}) \text { then } 4 \text { days } \\
\text { without treatment then } 10 \mathrm{mg} / \mathrm{kg} \\
\times 3 \text { days (oral) }\end{array}$ & Chlamydia & China \\
\hline Friedman et $a{ }^{24}$ & Cohort & - & $<28$ & 58 & - & 13 & $10-12 \mathrm{mg} / \mathrm{kg} \times 5$ days (oral) & Pertussis & USA \\
\hline Hammerschlag et $a^{25}$ & Cohort & - & $<28$ & 12 & - & 0 & $\begin{array}{l}20 \mathrm{mg} / \mathrm{kg} \text { single dose and } 20 \mathrm{mg} / \\
\mathrm{kg} / \text { day } \times 3 \text { days (oral) }\end{array}$ & Chlamydia & USA \\
\hline Eberly et $a^{26}$ & Cohort & - & $<28$ & 148 & - & 3 & NA & - & USA \\
\hline Viscardi et $a{ }^{27 *}$ & Pharmacokinetic & - & $<3$ & 13 & - & 7 & $20 \mathrm{mg} / \mathrm{kg}$ once & Ureaplasma & USA \\
\hline Hassan et $a^{28 *}$ & Pharmacokinetic & - & $<28$ & 14 & - & 10 & $10 \mathrm{mg} / \mathrm{kg}$ once & BPD & USA \\
\hline Tessema et $a^{29 *}$ & Pharmacokinetic & - & $<28$ & 16 & - & 0 & $10 \mathrm{mg} / \mathrm{kg}$ once & - & USA \\
\hline Zayas et $a \beta^{30 *}$ & Case report & - & 21 & 1 & - & 1 & NA & Chlamydia & USA \\
\hline
\end{tabular}

\section{*Preterm neonates.}

AEs, adverse event; AZT, azithromycin; BPD, bronchopulmonary dysplasia; CNS, central nervous system; IVH, intraventricular haemorrhage; IV, intravenous; NA, not applicable; PDA, Patent ductus arteriosus; PVL, periventricular leukomalacia; RCT, randomised controlled trials. 
Table 2 Classification and risk of adverse events from RCTs and observational studies $(n=324)$

\begin{tabular}{|c|c|c|c|c|}
\hline Classification & Adverse event & Number & $\begin{array}{l}\text { Risk of AE per } \\
1000 \text { neonates }\end{array}$ & $95 \% \mathrm{Cl}$ \\
\hline \multirow[t]{7}{*}{ Gastrointestinal } & Vomiting & 12 & 37 & 21 to 64 \\
\hline & Feeding intolerance/poor feeding & 10 & 31 & 16 to 57 \\
\hline & NEC & 8 & 25 & 12 to 49 \\
\hline & Abdominal tenderness & 6 & 19 & 8 to 41 \\
\hline & Diarrhoea & 4 & 12 & 5 to 33 \\
\hline & Other gastrointestinal symptoms & 13 & 40 & 24 to 68 \\
\hline & Total gastrointestinal $\mathrm{AE}$ & 53 & 163 & 128 to 209 \\
\hline \multirow[t]{3}{*}{ Respiratory } & $\mathrm{BPD}$ & 96 & 296 & 251 to 350 \\
\hline & Respiratory distress & 1 & 3 & 4 to 22 \\
\hline & Total respiratory AE & 97 & 299 & 253 to 354 \\
\hline \multirow[t]{5}{*}{ CNS } & At least grade 3 IVH & 29 & 90 & 63 to 127 \\
\hline & Abnormal hearing & 22 & 68 & 45 to 102 \\
\hline & PVL & 15 & 46 & 28 to 76 \\
\hline & Others & 4 & 12 & 5 to 33 \\
\hline & & 74 & 228 & 187 to 279 \\
\hline Hepatobiliary & Elevated transaminase & 16 & 49 & 31 to 80 \\
\hline Cardiovascular & PDA & 20 & 62 & 40 to 94 \\
\hline Metabolic & Hyperkalaemia & 2 & 6 & 2 to 25 \\
\hline \multirow[t]{3}{*}{ Others } & Sepsis & 11 & 34 & 19 to 61 \\
\hline & Other infections & 96 & 296 & 251 to 350 \\
\hline & Allergy & 2 & 6 & 2 to 25 \\
\hline Total & & 371 & & \\
\hline
\end{tabular}

\section{RESULTS}

A total of 11 articles involving 473 neonates were identified (figure 2). The majority of the studies (4 studies) were RCTs. There were three pharmacokinetic studies and three cohort studies (table 1). One case report was identified. The RCTs involved 211 neonates who received azithromycin and 198 controls. The cohort studies and PK studies involved 218 and 43 neonates, respectively. Three hundred and seventy-one AEs were reported. Adverse events were mainly respiratory (358/ 1000 neonate), neurological (273/1000 neonates) and gastrointestinal (196/1000 neonates) in origin. Vomiting (44/1000 neonates), diarrhoea (15/1000 neonates), abdominal tenderness (22/1000 neonates) and feeding intolerance $(37 / 1000$ neonates $)$, were the most frequently reported gastrointestinal symptoms. The majority of the respiratory and neurological AEs were usually associated with prematurity (table 2).

\section{Evidence from RCTs}

Two of the four RCTs were placebo controlled. Intravenous azithromycin, $10 \mathrm{mg} / \mathrm{kg} /$ day, was administered for 1 week followed by a 5 -week course of $5 \mathrm{mg}$ / $\mathrm{kg}$ /day as prophylaxis for BPD in both studies. ${ }^{20}{ }^{21} \mathrm{~A}$ third study administered $5 \mathrm{mg} / \mathrm{kg} /$ day for 1 week after an initial 1 week course of oral $10 \mathrm{mg} / \mathrm{kg} /$ day. ${ }^{22}$ The patients in the comparator arm of this study were not given any treatment. Meta-analysis of the incidence of BPD between neonates administered azithromycin and the control group in the three studies showed that azithromycin significantly reduced the risk of BPD in extremely premature neonates $(\mathrm{RR}=0.83,95 \% \mathrm{CI} 0.71$ to

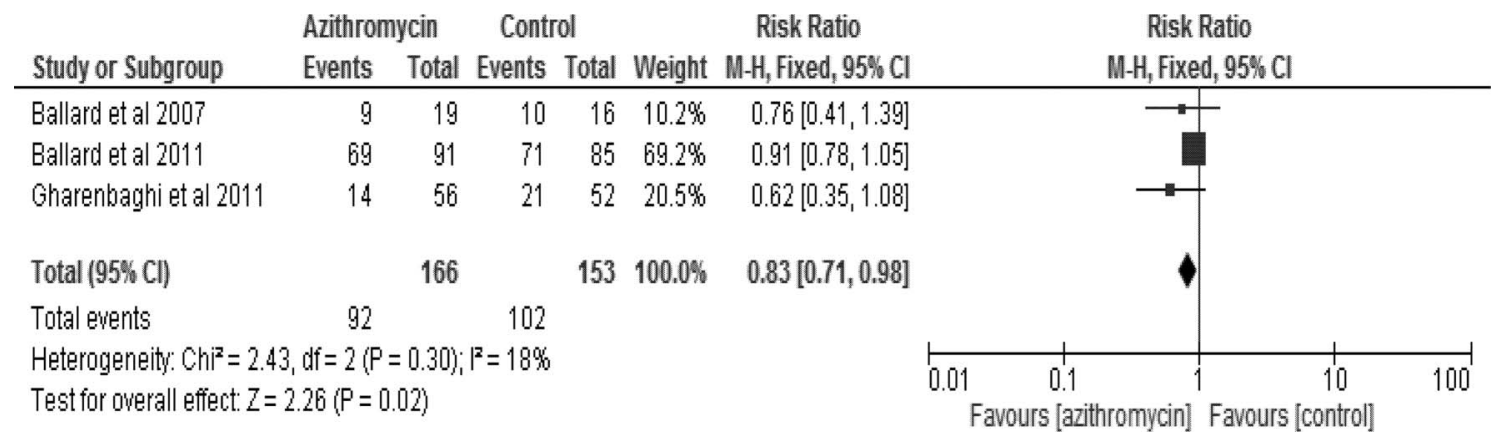

Figure 3 Relative risks of BPD in azithromycin and untreated/placebo treated preterm neonates. BPD, bronchopulmonary dysplasia. 
Figure 4 Funnel plot to determine publication bias.

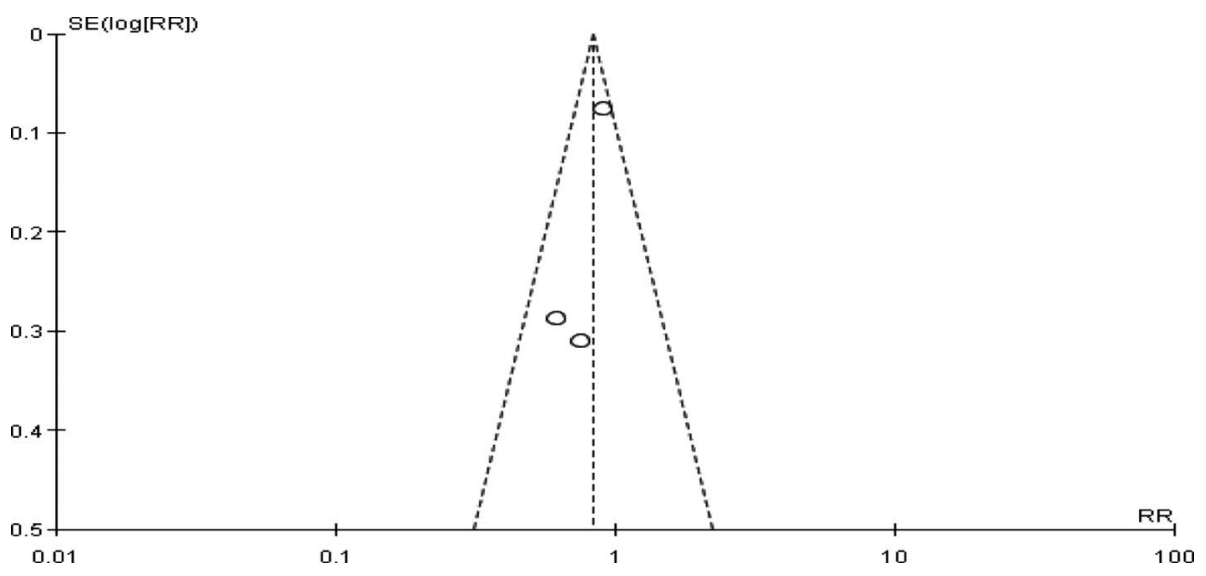

0.98, $\mathrm{p}=0.02$ ) (figure 3): $55 \%$ of preterm neonates given azithromycin developed BPD compared to $67 \%$ of those without treatment or those given placebo. Funnel plots of these RCTs show no publication bias (figure 4). The fourth study compared the efficacy of azithromycin with erythromycin for the treatment of chlamydia conjunctivitis. ${ }^{23}$ Ninety-six per cent of children treated with 3 days intravenous $10 \mathrm{mg} / \mathrm{kg}$ and subsequent 4 days oral dose azithromycin recovered compared with $76 \%$ of those given twice daily $10 \mathrm{mg} / \mathrm{kg}$ erythromycin for 3 days followed by 11 days of thrice daily oral erythromycin. A significantly higher cure rate $(p=0.03)$ was achieved with azithromycin than with erythromycin.

There was no significant difference in the incidence of elevated liver enzymes between the azithromycin and placebo group $(\mathrm{p}=0.76)$ (figure 5). All cases of elevated transaminases (16 cases) were reported in a single RCT. $^{20}$ There were 13 cases of elevated transaminases in the control group of this study. Only one placebo/no treatment controlled trial reported vomiting as an adverse event, with no significant difference between the azithromycin group and the neonates without treatment $(p=0.79)$. The other AEs reported in the placebo/no treatment controlled RCTs were usually associated with prematurity (intraventricular haemorrhage, periventricular leucomalacia, necrotising enterocolitis, patent ductus arteriosus and hearing abnormalities) and there were no significant differences between azithromycin and the comparator arms. ${ }^{20-22}$ A Chinese study reported more cases of diarrhoea, abdominal pain and reduced appetite in the children treated with oral erythromycin (after 3 days of intravenous treatment), compared with those administered azithromycin. ${ }^{23}$

\section{Evidence from observational studies}

Two cohort studies were identified. One of these studies involved a cohort of neonates given either azithromycin or erythromycin following exposure to a patient with pertussis. $^{24}$ Fifty-eight neonates received azithromycin while 18 were given erythromycin. None of the neonates developed infantile hypertrophic pyloric stenosis (IHPS). Fourteen (24\%) of those given azithromycin experienced AEs. These included three cases each of irritability, candidiasis and vomiting; two cases of rash and one case each of diarrhoea, abdominal pain and blood in the stool. Ten $(56 \%)$ of the neonates given erythromycin experienced AEs. There was a significantly lower incidence of diarrhoea $(p=0.01)$ in the azithromycin-treated compared with erythromycintreated neonates. The incidences of other AEs were not significantly different.

The second observational study involved 12 neonates who received varying doses of azithromycin suspension for the treatment of chlamydia conjunctivitis. ${ }^{25}$ Three of the 5 neonates $(60 \%)$ administered a single dose of $20 \mathrm{mg} / \mathrm{kg}$ became culture negative; while 6 of the 7

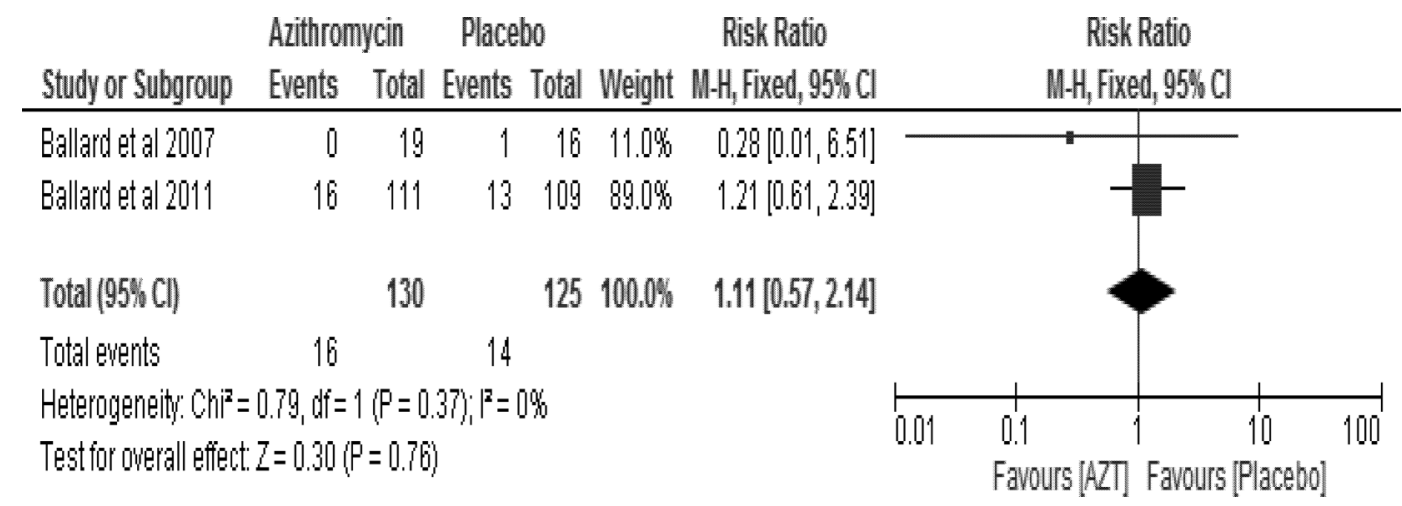

Figure 5 Relative risk of elevated transaminase in azithromycin and placebo treated neonates. 
(86\%) given $20 \mathrm{mg} / \mathrm{kg} /$ day for 3 days became culture negative. No AEs were reported in this study.

\section{Retrospective study}

A single retrospective cohort study was identified. This study explored the risk of IHPS in neonates exposed to azithromycin and erythromycin, using the US military health system (MHS) database. Of the one hundred and forty-eight neonates (0-14 days old) treated with azithromycin, 3 (2\%) developed IHPS. Nine (3\%) of the 291 neonates (0-14 days) given erythromycin had IHPS. ${ }^{26}$

\section{Pharmacokinetic studies}

A single dose of $20 \mathrm{mg} / \mathrm{kg}$ was administered in a pharmacokinetic study ${ }^{27}$ and a $10 \mathrm{mg} / \mathrm{kg}$ single dose was administered in two other pharmacokinetic studies. ${ }^{28} 29$ All the AEs reported in two of these studies were usually associated with prematurity and none was attributed to azithromycin. ${ }^{27} 28$ There were four cases of intraventricular haemorrhage, three of hearing loss, two of necrotising enterocolitis, one each of periventricular leucomalacia, respiratory distress syndrome, pneumomediastinum and hyperbilirubinaemia. No AEs were observed in the third study. ${ }^{29}$

\section{Case report}

There was one case report of pyloric stenosis in a 5-week old infant who had received 5 days of oral azithromycin at 3 weeks of life as treatment for chlamydia conjunctivitis. ${ }^{30}$

\section{DISCUSSION}

Only a small population of neonates have been treated with azithromycin and no major $\mathrm{AE}$ has been documented. This systematic review shows that azithromycin significantly reduces the risk of BPD in neonates and is also effective in the treatment of chlamydia conjunctivitis. A previous systematic review has also demonstrated the efficacy of azithromycin in the prevention of BPD. ${ }^{31}$ Macrolide antibiotics are inhibitors of ureaplasma. The relationship between ureaplasma infection and BPD has been explored with varying outcomes reported from different studies. ${ }^{15}{ }^{17}{ }^{32}$ We have also identified two off-label studies demonstrating the efficacy of azithromycin against chlamydia trachomatis in neonates. Previous studies have reported the susceptibility of chlamydia to azithromycin. ${ }^{33}$ Azithromycin was administered once daily in all studies because of its long half-life, which is estimated to be between 26 and $83 \mathrm{~h}$ in neonates. ${ }^{25}$ The dose and duration of treatment with azithromycin varied across the studies. This may be due to its off-label use and the absence of a standardised dosing regimen for the drug in this age group. Very few studies have been conducted in neonates; hence the safety and efficacy of different dosing regimens for different indications have not been established.
The majority of the AEs reported in preterm neonates were related to prematurity and were unlikely to be caused by azithromycin. Results from one of the studies, however, showed that azithromycin had a better safety profile than erythromycin in neonates. Diarrhoea, abdominal discomfort and reduced appetite were less frequent in azithromycin treated neonates. In another study, $2 \%$ and $3 \%$, respectively, of neonates exposed to azithromycin and erythromycin within 14 days of life developed IHPS. ${ }^{26}$ Both erythromycin and azithromycin are gastric motilin receptor agonists. ${ }^{34}$ Activation of these receptors by erythromycin with consequent increased pyloric contractions has been hypothesised as a possible cause of pyloric hypertrophy in neonates. ${ }^{35}$ The association between erythromycin and pyloric stenosis has been demonstrated in previous studies. High dose and early neonatal exposure to the drug within the first 14 days of life are known risk factors. ${ }^{36}$ Azithromycin, similarly to erythromycin, binds to and activates the motilin receptors. ${ }^{37}$ Erythromycin is, however, believed to have a stronger gastrointestinal prokinetic effect than azithromycin. ${ }^{38}$ These drugs are slightly structurally different, with erythromycin having a 14-C member heterocyclic ring and azithromycin a 15 member ring. ${ }^{39}$ The effect of the structural differences on motilin receptor binding and IHPS requires further exploration. Postnatal exposure to macrolides from breast milk has also been associated with IHPS. ${ }^{40}$ Further studies are required to determine the relationship between neonatal azithromycin use and IHPS.

Although prolonged $\mathrm{QT}_{\mathrm{c}}$ interval and torsades de pointes had been reported in azithromycin-treated adults, ${ }^{41}$ none of the reviewed studies evaluated neonates for arrhythmia. There is a documented case of arrhythmia in an infant following azithromycin overdose,${ }^{42}$ and spiramycin, which is a structurally similar macrolide, has been associated with neonatal arrhythmia. ${ }^{43}$ Prolonged $\mathrm{QT}_{\mathrm{c}}$ interval can be normal in the first few days of life in premature neonates, hence it is difficult to identify drug-induced aetiology during this period. ${ }^{44}$

In conclusion, azithromycin significantly reduces the risk of BPD in preterm neonates and it is effective for the treatment of chlamydia conjunctivitis. It has a better safety profile than erythromycin in the limited number of treated neonates. The relationship between azithromycin and IHPS requires further investigation. More studies are required to determine a safe and effective dose for azithromycin in neonates.

Acknowledgements This work is part of the TINN2 network (Collaborative Project) supported by the European Commission under the Health Cooperation Work Programme of the 7th Framework Programme (grant agreement number 260908). The authors wish to thank Sally Hinchcliffe, Medical Statistician at the Royal Derby Hospital, for her statistical advice on this paper.

Contributors IC, SK, EJ-A and HS conceived the idea; CS performed the literature search and extracted the data. OE updated the search and verified the extracted data. OE produced the first draft of the manuscript. All the authors contributed to the subsequent and final drafts of the manuscript. 
Funding Supported by the European Commission under the Health Cooperation Work Programme of the 7th Framework Programme (grant agreement number 260908).

Competing interests None declared.

Provenance and peer review Not commissioned; externally peer reviewed.

Data sharing statement No additional data are available.

Open Access This is an Open Access article distributed in accordance with the Creative Commons Attribution Non Commercial (CC BY-NC 4.0) license, which permits others to distribute, remix, adapt, build upon this work noncommercially, and license their derivative works on different terms, provided the original work is properly cited and the use is non-commercial. See: http:// creativecommons.org/licenses/by-nc/4.0/

\section{REFERENCES}

1. Clavenna A, Bonati M. Differences in antibiotic prescribing in paediatric outpatients. Arch Dis Child 2011;96:590-5.

2. Franchi $C$, Sequi $M$, Bonati $M$, et al. Differences in outpatient antibiotic prescription in Italy's Lombardy region. Infection 2011;39:299-308.

3. Grijalva CG, Nuorti JP, Griffin MR. Antibiotic prescription rates for acute respiratory tract infections in US ambulatory settings. JAMA 2009;302:758-66.

4. Zuckerman JM. Macrolides and ketolides: azithromycin, clarithromycin, telithromycin. Infect Dis Clin North Am 2004;18:621-49.

5. Heads of Medicines Agencies. Azithromycin part II. http://www.hma. eu/fileadmin/dateien/Human_Medicines/CMD_h_/Paediatric_ Regulation/Assessment Reports/Article 45 work-sharing/ Azithromycin_II-2012_09-Art.45_PublicAR.pdf (accessed 18 Feb 2014)

6. Langtry HD, Balfour JA. Azithromycin. A review of its use in paediatric infectious diseases. Drugs 1998;56:273-97.

7. Joint Formulary Committee. British National Formulary (online). London: BMJ Group and Pharmaceutical Press. http://www. medicinescomplete.com (accessed 17 Jul 2013).

8. Medicine and healthcare products regulatory agency. Azithromycin $500 \mathrm{mg}$ powder for infusion. http://www.mhra.gov.uk (accessed 17 Jul 2013).

9. Summary of product characteristics: Azyter $15 \mathrm{mg} / \mathrm{g}$ eye drops. http://www.mhra.gov.uk (accessed 19 Jul 2013)

10. Full prescribing information: AzaSite $囚$. http://www.accessdata.fda. gov (accessed 19 Jul 2013)

11. Ruuskanen O. Safety and tolerability of azithromycin in pediatric infectious diseases: 2003 update. Pediatr Infect Dis J 2004;23(2 Suppl):S135-9.

12. Ray WA, Murray KT, Hall K, et al. Azithromycin and the risk of cardiovascular death. N Engl J Med. 2012;366:1881-90.

13. FDA drug safety communication. Azithromycin (Zithromax or Zmax) and the risk of potentially fatal heart rhythms. http://www.fda.gov (accessed 9 Jul 2013)

14. Taylor-Robinson D, Bébéar C. Antibiotic susceptibilities of mycoplasmas and treatment of mycoplasmal infections. J Antimicrob Chemother 1997;40:622-30.

15. Koh E, Kim S, Kim IS, et al. Antimicrobial susceptibilities of Ureaplasma urealyticum and Mycoplasma hominis in pregnant women. Korean J Clin Microbiol 2009;12:159-62.

16. Wang EL, Ohlsson A, Kellner JD. Association of Ureaplasma urealyticum colonization with chronic lung disease of prematurity: results of a metaanalysis. J Pediatr 1995;127:640-4.

17. Schelonka RL, Katz B, Waites KB, et al. Critical appraisal of the role of Ureaplasma in the development of bronchopulmonary dysplasia with metaanalytic techniques. Pediatr Infect Dis J 2005;24:1033-9.

18. Tiwari T, Murphy TV, Moran J. Recommended antimicrobial agents for the treatment and postexposure prophylaxis of pertussis: 2005 CDC Guidelines. MMWR Recomm Rep 2005;54(RR-14):1-16.

19. Cochrane bias method group: Assessing risk of bias in included studies. http://bmg.cochrane.org/assessing-risk-bias-includedstudies. (accessed 10 Jul 2013).

20. Ballard HO, Shook LA, Bernard P, et al. Use of azithromycin for the prevention of bronchopulmonary dysplasia in preterm infants: a randomised, double-blind, placebo controlled trial. Pediatr Pulmonol 2011;46:111-18.

21. Ballard HO, Anstead MI, Shook LA. Azithromycin in the extremely low birth weight infant for the prevention of bronchopulmonary dysplasia: a pilot study. Respir Res 2007;8:41.

22. Gharehbaghi MM, Peirovifar A, Ghojazadeh M, et al. Efficacy of azithromycin for prevention of bronchopulmonary dysplasia (BPD). Turk J Med Sci 2012;42:1070-5.

23. Dong Z. Efficacy of azithromycin in the treatment of Chlamydia trichomatis conjunctivitis in neofant. Chin J Antibiot 2005;30:428-9.

24. Friedman DS, Curtis CR, Schauer SL, et al. Surveillance for transmission and antibiotic adverse events among neonates and adults exposed to a healthcare worker with pertussis. Infect Control Hosp Epidemiol 2004;25:967-73.

25. Hammerschlag MR, Gelling M, Roblin PM, et al. Treatment of neonatal chlamydial conjunctivitis with azithromycin. Pediatr Infect Dis J 1998;17:1049-50.

26. Eberly MD, Eide MB, Thompson JL, et al. Azithromycin in early infancy and pyloric stenosis. Pediatrics 2015;135:483-8.

27. Viscardi RM, Othman AA, Hassan HE, et al. Azithromycin to prevent bronchopulmonary dysplasia in ureaplasma-infected preterm infants: pharmacokinetics, safety, microbial response, and clinical outcomes with a 20-milligram-per-kilogram single intravenous dose. Antimicrob Agents Chemother 2013;57:2127-33.

28. Hassan HE, Othman AA, Eddington ND, et al. Pharmacokinetics, safety, and biological effects of azithromycin in extremely preterm infants at risk for ureaplasma colonization and bronchopulmonary dysplasia. J Clin Pharmacol 2011;51:1264-75.

29. Tessema E, Warrier I, Lulic-Botica M, et al. Pharmacokinetics (PK) of intravenous azithromycin in preterm newborns. Neonatology 2007;92:279-95.

30. Zayas J. A 5 week old male presenting with infantile hypertrophic pyloric stenosis following azithromycin therapy: a case report. $J$ Investig Med 2010;58:415.

31. Nair V, Loganathan P, Soraisham AS. Azithromycin and other macrolides for prevention of bronchopulmonary dysplasia: a systematic review and meta-analysis. Neonatology 2014;106:337-47.

32. Kallapur SG, Kramer BW, Jobe AH. Ureaplasma and BPD. Semin Perinatol 2013;37:94-101.

33. Welsh L, Gaydos C, Quinn T. In vitro evaluation of activities of azithromycin, erythromycin, and tetracycline against Chlamydia trachomatis and Chlamydia pneumoniae. Antimicrob Agents Chemother 1992;36:291-4.

34. Peeters T, Matthijs G, Depoortere I, et al. Erythromycin is a motilin receptor agonist. Am J Physiol 1989;257:G470-4.

35. Cooper WO, Griffin MR, Arbogast $\mathrm{P}$, et al. Very early exposure to erythromycin and infantile hypertrophic pyloric stenosis. Arch Pediatr Adolesc Med 2002;156:647-50.

36. Maheshwai N. Are young infants treated with erythromycin at risk for developing hypertrophic pyloric stenosis? Arch Dis Child 2007;92:271-3.

37. Broad J, Sanger GJ. The antibiotic azithromycin is a motilin receptor agonist in human stomach: comparison with erythromycin. $\mathrm{Br} \mathrm{J}$ Pharmacol 2013;168:1859-67.

38. Klein JO. History of macrolide use in paediatrics. Pediatr Infect Dis J 1997;16:427-31.

39. Zuckerman JM, Qamar F, Bono BR. Review of macrolides (azithromycin, clarithromycin), ketolids (telithromycin) and glycylcyclines (tigecycline). Med Clin North Am 2011;95: 761-91.

40. Sørensen HT, Skriver MV, Pedersen L, et al. Risk of infantile hypertrophic pyloric stenosis after maternal postnatal use of macrolides. Scand J Infect Dis 2003;35:104-6.

41. Howard PA. Azithromycin-induced proarrhythmia and cardiovascular death. Ann Pharmacother 2013;47:1547-51.

42. Tilelli JA, Smith KM, Pettignano R. Life-threatening bradyarrhythmia after massive azithromycin overdose. Pharmacotherapy 2006;26:147-50.

43. Stramba-Badiale M, Nador F, Porta N, et al. QT interval prolongation and risk of life-threatening arrhythmias during toxoplasmosis prophylaxis with spiramycin in neonates. Am Heart $J$ 1997;133:108-11.

44. Ulrich TJ, Ellsworth MA, Carey WA, et al. Heart-rate-corrected QT interval evolution in premature infants during the first week of life. Pediatr Cardiol 2014;35:1363-9. 